\begin{tabular}{|c|c|c|c|}
\hline \multirow{2}{*}{$\begin{array}{r}\text { Case Reports in } \\
\text { Gastroenterology }\end{array}$} & \multicolumn{2}{|c|}{ Case Rep Gastroenterol 2016;10:406-409 } & \multirow[b]{2}{*}{$\begin{array}{l}\text { Karger } \\
\text { Open access }\end{array}$} \\
\hline & $\begin{array}{l}\text { DOI: 10.1159/000448065 } \\
\text { Publisned onine.: August 9, } 2016\end{array}$ & $\begin{array}{l}\text { (c) } 2016 \text { The Author(s) } \\
\text { Published by S. Karger AG, Basel } \\
\text { www.karger.com/crg }\end{array}$ & \\
\hline & $\begin{array}{l}\text { This article is licensed under t } \\
\text { International License (CC BY-NC } \\
\text { Usage and distribution for comm }\end{array}$ & $\begin{array}{l}\text { nons Attribution-NonCommerci } \\
\text { ger.com/Services/OpenAccessLic } \\
\text { uires written permission. }\end{array}$ & \\
\hline
\end{tabular}

Single Case

\title{
An Unusual Cause of Rectal Stenosis
}

\author{
Maja Gruber ${ }^{a} \quad$ Ida Füglistaler ${ }^{b} \quad$ Andreas Zettel $^{c} \quad$ Mark Fox $^{a}$ \\ Michael Manz ${ }^{\mathrm{a}}$ \\ ${ }^{a}$ Division of Gastroenterology, St. Claraspital, Basel, Switzerland; ${ }^{\mathrm{b}}$ Division of Surgery, \\ St. Claraspital, Basel, Switzerland; ' Viollier Institute, Pathology, Allschwil, Switzerland
}

\section{Keywords}

Solitary rectal ulcer $\cdot$ Stenosis $\cdot$ Constipation $\cdot$ Mucous discharge

\begin{abstract}
Solitary rectal ulcer syndrome (SRUS) is a benign disease that is often misdiagnosed. It is characterized by a combination of symptoms, endoscopic findings and histology. Patients present with constipation, rectal bleeding, mucous discharge, pain and a sensation of incomplete defecation. There are many different manifestations of this disease, with or without rectal prolapse. We report an unusual presentation of SRUS as a circular stenosis in a middleaged male.

(C) 2016 The Author(s)

Published by S. Karger AG, Basel
\end{abstract}

\section{Introduction}

Solitary rectal ulcer syndrome (SRUS) is a chronic, benign disorder of defecation. It can present with diverse endoscopic findings including ulcers (solitary and multiple), erythematous patches, polypoid/nodular growth, telangiectasia and even rectal stenosis. Common symptoms include bleeding or mucous discharge per rectum, abdominal pain, straining, prolapse, constipation or diarrhea, the sensation of incomplete evacuation or perianal pain.

Because of the wide range of endoscopic findings and symptoms and because SRUS mimics other disorders such as neoplasm and inflammatory bowel disease, SRUS can be difficult to diagnose. Thus, SRUS is a misnomer: ulcers are not always present, and the le- 
sions are not always solitary. Histology is one of the most important components to diagnose SRUS as fibromuscular obliteration is pathognomonic of the condition. The etiology of SRUS remains uncertain; however, in addition to mechanical injury, local ischemia from pressure of impacted stool and prolapse may be an important contributing factor.

This syndrome is often misdiagnosed due to the lack of familiarity of clinicians with the disease [1]. Opinions regarding the best treatment options range from conservative management based on stool regulation to local endoscopic therapy and surgical therapies.

\section{Case Presentation}

A 58-year-old male patient presented for further investigation of chronic constipation in our outpatient clinic. He reported obstructive defecation with the need for manual disimpaction (four times a week). Rectal bleeding and mucous discharge were present on a daily basis. A thorough medical history reveals a metabolic syndrome (arterial hypertension, adipositas and diabetes mellitus type II). His regular medication included oral antidiabetics and an antihypertensive agent, as well as different kinds of laxatives (bulking agents, osmotic agents, prokinetic and combinations). He did not smoke and did not consume alcohol on a regular basis. At physical examination, we saw a healthy patient in good general health status. The abdomen was adipose, with normal palpation and percussion. Initial rectal examination revealed a gaping anus with low sphincter tonus and mucous discharge, the perianal skin was slightly inflamed. We performed laboratory examinations (including differential blood count, thyroid hormone levels, electrolytes, blood glucose liver, glycated hemoglobin and kidney values), which were all normal. Systemic conditions explaining chronic constipation were not present.

A sigmoidoscopy 2 years previously had revealed an ulcerative proctitis of unclear origin; histologically compatible with nonsteroidal anti-inflammatory induced lesions. The patient denied the consumption of such substances. Proctological examination revealed anal prolapse (confirmed at MR defecography) and sigmoidoscopy showed a circular stenosis in the distal rectum with extensive ulceration of one third of the lumen. There were no other pathologic findings at sigmoidoscopy. Balloon dilatation of the stenosis was performed at endoscopy. At a later date, a surgical mucosectomy was performed to reduce the anal prolapse. These procedures led to a temporary improvement in symptoms. Prolapse symptoms and bleeding episodes occurred less frequently (twice a week). The need for manual disimpaction decreased to once a week. However, 18 months later, the patient presented again with severe, recurrent symptoms. He again suffered from daily bleeding, mucous discharge and obstinate constipation.

Repeat endoscopic examination demonstrated an ulcerative stenosis in the distal rectum (10 cm from the anocutaneous line) with an irregular surface of the mucosa compatible with chronic mechanical injury (fig. 1a). Macroscopically and microscopically, there was no suspicion of malignancy. Because of the substantial restriction in quality of life, the patient underwent an anterior rectum resection with rectopexy (fig. 1b). Histological workup showed focal ulceration, fibrino-leucocytar exudation, hypertrophied muscularis mucosae and regeneration crypts compatible with mucosal prolapse/SRUS (fig. 1c). The postoperative course was complicated; despite the peri- and postoperative use of low-molecularweight heparin, he suffered from unilateral segmental lung embolism. The therapeutic anticoagulation with liquemin led to a hemodynamic relevant bleeding at the abdominal incision. The hematoma had to be evacuated; further surveillance in the intensive care unit was 
uneventful. Blood packs did not need to be transfused, and the wound healing was satisfactory. The patient was discharged from hospital on postoperative day 21 with oral anticoagulation (Xarelto ${ }^{\circledR}$ ). At follow-up 2 months later, the patient was free of defecation problems, and laxatives or manual disimpaction was not necessary anymore. No further bleeding did (not even under anticoagulation).

\section{Discussion}

SRUS is an uncommon, benign disease that is often misdiagnosed. It is a chronic disorder characterized by a combination of symptoms, endoscopic findings and histology. Patients present with constipation, rectal bleeding, mucous discharge, pain and the sensation of incomplete defecation. Clinically, rectal prolapse may or may not be evident; however, the mechanism of disease is thought to be mechanical trauma due to prolapse of the rectal mucosa into the anal canal during repeated, often frustrating attempts to defecate. Chronic hypoperfusion induces ischemic injury to the rectal mucosa and may also contribute to chronic ulceration and failure to heal. Local effects of retained stool in the distal rectum may also play a role.

Endoscopic findings include erythematous patches, mucosal ulceration (solitary or multiple) and polypoid lesions. These are most often found on the anterior wall of the rectum; however, in this unusual and advanced case, a circular stenosis was produced. The diagnosis of SRUS was secured by the presence of fibromuscular obliteration of the lamina propria, hypertrophied muscularis mucosae, chronic inflammation, mucosal erosion/ulceration and signs of mucosal regeneration. Signs of dysplasia and neoplasia were not present. These are characteristic histologic findings in this condition.

Several treatment options are available for the management of SRUS. The option selected will differ depending on the clinical and endoscopic findings and on the severity of symptoms. Nonsevere cases often profit from lifestyle modifications, diet, bulking agents or laxatives, behavioral advice (e.g. toilet habits, psychological factors), physiotherapy and reassurance. If this conservative treatment fails or cases are more severe (e.g. with prolapse), more intensive therapy is required. Endoscopic treatments such as resection of polypoid mucosal prolapse or rubber band ligation can be evaluated. In our case, endoscopic balloon dilatation was used. Surgical interventions include ulcer excision, treatment of internal or external prolapse (rectopexy, mucosal resection), proctectomy (especially when intractable pain is present) or even diverting colostomy [2].

\section{Conclusion}

Although SRUS is a rare disease, it should be considered in the differential diagnosis of uncommon pathologic findings in the rectum, including polypoid tumors and stenosis. Especially histological workup of retained specimens is very helpful in distinguishing SRUS from other conditions. 
Gruber et al.: An Unusual Cause of Rectal Stenosis

\section{Statement of Ethics}

All procedures were in accordance with the ethical standards. Informed consent was obtained from the patient for being included in the report.

\section{Disclosure Statement}

All authors report no conflicts of interest related to this paper.

\section{References}

1 Abid S, Khawaja A, Bhimani SA, et al: The clinical, en doscopic and histological spectrum of the solitary rectal ulcer syndrome: a single-center experience of 116 cases. BMC Gastroenterol 2012;12:72.

-2 Zhu QC, Shen RR, Quin HL, Wang Y: Solitary rectal ulcer syndrome: clinical features, pathophysiology, diagnosis and treatment strategies. World J Gastroenterol 2014;20:738-744.
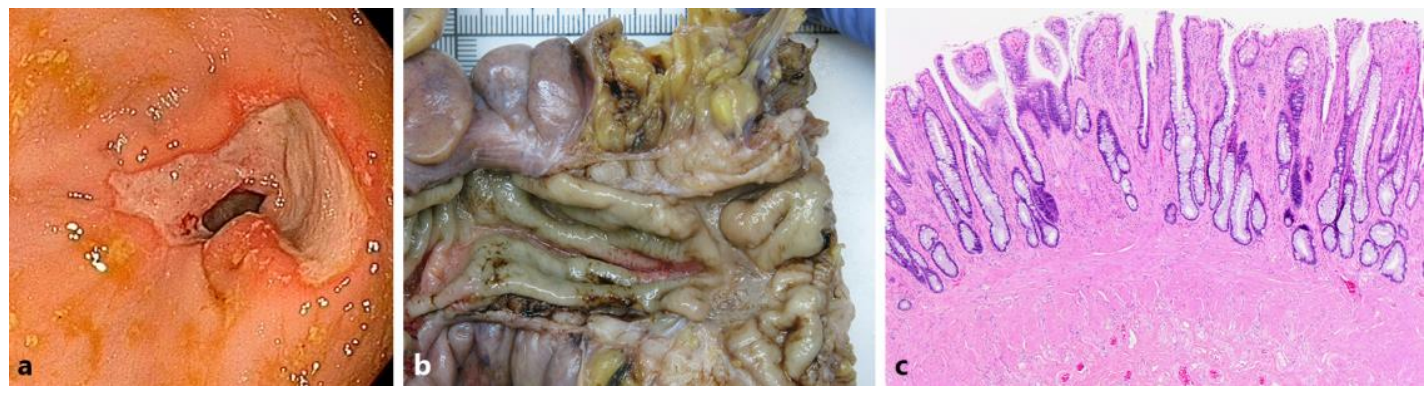

Fig. 1. a Endoscopic appearance of a solitary rectal ulcer. In this case, circular stenosis and ulceration can be seen. $\mathbf{b}$ Macroscopic photograph of the surgical specimen. At the right margin, stenosis and ulceration are visible. The mucosa of the proximal rectum and sigma is normal. c Histological picture showing fibromuscular obliteration and crypt distortion. HE. $\times 40$. 